\title{
Characterization of Staphylococcus species isolated from raw milk and milk products (Iben and jben) in North Morocco
}

\author{
Abdrezzak Bendahou, ${ }^{1,2}$ Mariam Lebbadi, ${ }^{3}$ Latifa Ennanei, ${ }^{2}$ \\ Fatima Z. Essadqui, ${ }^{1}$ Mohammed Abid. ${ }^{2}$ \\ ${ }^{1}$ Département de Sécurité Alimentaire \& Environnementale, Institut Pasteur, Tanger, Maroc \\ ${ }^{2}$ Département de Recherche scientifique, Laboratoire de biologie moléculaire, Institut Pasteur, Tanger, Maroc \\ ${ }^{3}$ Département des Sciences de la vie, Faculté des sciences \& technique, Tanger, Maroc
}

\begin{abstract}
Background: To investigate the incidence and antibiotic resistance of staphylococcal strains isolated from milk and milk products and to trace the ecological origin of the Staphylococcus aureus isolated.

Methodology: Eighty-one samples of raw milk, Iben (whey) and jben (cheese) were analyzed for the presence of staphylococcal strains. Isolates were identified by Gram stains, tests for coagulase, the API staph system and the WalkAwayß 40/96, which also determines the antimicrobial susceptibility profiles. The $S$. aureus strains were biotyped, and variable regions of the coagulase gene were amplified using the polymerase chain reaction.

Results: The identification results showed a predominance of coagulase-negative staphylococci (54\%). Coagulase-positive staphylococci that were identified were divided into 3 groups comprising S. aureus (40\%), Staphylococcus intermedius (2 \%) and Staphylococcus hyicus (4\%). Among the S. aureus that was isolated, biotype C was the predominant biotype. Among 40 coagulase gene PCR-amplification products, 37 produced a single band, while 3 isolates produced two bands.

The antimicrobial susceptibility-profile of the staphylococcal strains revealed a high incidence of $S$. aureus to penicillin $\mathrm{G}$. In addition, Staphylococcus lentus presented considerable resistance to the oxacillin, erythromycin and lincomycin.

Conclusions: The presence of staphylococci in raw milk, lben and jben in areas of northern Morocco poses a health hazard, so it is necessary for the public health inspectors to properly examine the conditions during production, storage and commercialization of all products made with unpasteurized milk.
\end{abstract}

Key Words: milk products, Staphylococcus, coagulase-gene typing, biotyping, antimicrobial susceptibility.

J Infect Developing Countries 2008; 2(3):218-225.

Received 13 March 2008 - Accepted 29 April 2008

Copyright $@ 2008$ Bendahou et al. This is an open access article distributed under the Creative Commons Attribution License, which permits unrestricted use, distribution, and reproduction in any medium, provided the original work is properly cited.

\section{Introduction}

Staphylococcal food poisoning (SFP) is one of the most prevalent causes of gastroenteritis worldwide [1]. Symptoms of SFP have a rapid onset (2 to 6 hours) of abdominal cramps, nausea, and vomiting, sometimes followed by diarrhoea $[2,3]$. Patients become symptomatic after ingestion of thermostable staphylococcal enterotoxins (SE) of an approximate dose of 0.1 to $1.0 \mathrm{mg} / \mathrm{kg}$ of body weight [4]. Since SE are more stable than $S$. aureus bacteria, it is possible to test a food product and obtain negative $S$. aureus culture results and positive SE tests. The hazard to public health is particularly linked to the ability of $50 \%$ of these strains to produce thermostable enterotoxins associated with food poisoning [5]. Milk and milk products are common vehicles for staphylococcal food poisoning [6-11]. They have frequently been implicated in SFP, and often contaminated raw milk is involved [2]. These products are highly susceptible to a variety of microorganisms because of their high nutritive value and complex chemical composition. The biological changes produced by these organisms can be either desirable or undesirable. They may have a useful function in the preparation of fermented milk products such as lben (whey) and jben (cheese) or they may have undesirable effects and produce changes in the odour, colour, taste, texture or appearance of the food. Furthermore, most of these bacteria produce toxins and cause food poisoning frequently. The presence of the pathogen depends on ingestion of contaminated feed followed by amplification in bovine hosts and faecal dissemination in the farm environment. The final outcome of this cycle is a self-maintained 
reservoir of a pathogen that can reach the human population by direct contact, ingestion of raw contaminated food (raw milk, cheese or whey made with raw milk), or contamination during the processing of food. Isolation of strains with similar biotypes from dairy farms and human cases and outbreaks substantiate this hypothesis [12].

Raw milk and milk products such as Iben (whey) and jben (Moroccan traditional fresh cheese) are widely manufactured and consumed by the peoples of North Morocco. However, these products have not been subjected to hygiene or sanitary control, because they are made at home. The incidence of staphylococcal food poisoning due to the consumption of dairy products is not uncommon in our country. The contamination of these products can be attributed to the occurrence of coagulase-positive staphylococci. These organisms can gain access to milk (raw material) either by direct excretion from udders with clinical and sub-clinical staphylococcal mastitis or by contamination. The contaminants reach the products either during cooling or handling after cooking [13]. Several easy steps can be taken to lower the risk and to render milk and milk products safe for consumption. Proper sanitary measures are needed to improve the hygienic conditions during milking, storage, transport, and manufacturing of cheese and whey in order to guarantee the quality of these popular products in North Morocco. These measures must include a program of sanitary education for the milking personnel, cheese, and whey producers.

In Morocco, studies on the relationship between origin, biotype and antibiotic resistance of staphylococcal strains isolated from milk and milk products have not yet been conducted, except works which have dealt with 56 strains isolated from thirty samples of soft fresh traditional Moroccan cheeses made from fresh milk and collected at three milk farms in the city of Rabat. The results show that $16(29 \%)$ of the strains are enterotoxigenic and 40 (71\%), 12 (22\%) and 4 $(7 \%)$ belonged to ovine, human and unspecified biovars, respectively [14].

The objective of the present study was to investigate the incidence and antibiotic resistance of staphylococci isolated from raw milk and products made with raw milk, such lben and jben, collected from various locations of the northern rural areas of Morocco. The study further aimed to trace the ecological origin of the $S$. aureus strains using the simplified scheme of Devriese [15] and also to use $\operatorname{coA}$ gene polymorphism to identify $S$. aureus subtypes.

\section{Materials \& Methods}

A total of 81 samples of milk and milk products consisting of raw milk (27), Iben (27) and jben (27) were aseptically collected on a random basis from different localities (weekly rural markets) in North Morocco [Tanger, Tetouan and Larache] between May 2005 and May 2006. Each locality was visited monthly (except in bad weather, when farmers cannot offer their products). Three samples consisting of 1 raw milk, 1 jben and 1 lben were collected during each visit so that at least nine samples were collected monthly. All the samples were placed in sterile plastic bags and immediately taken in a container containing ice cubes to the laboratory for bacteriological analysis.

\section{Isolation and identification of Staphylococcus isolates}

Twenty-five grams of each cheese sample and $25 \mathrm{ml}$ of raw milk and lben were stirred separately into $225 \mathrm{ml}$ of sterile buffered peptone water. Baird-Parker plates were then spread with $0.1 \mathrm{ml}$ of the dilution of each sample. Additional plates were prepared with successive $1 / 10$ dilutions. The plates were incubated for 48 hours at $37^{\circ} \mathrm{C}$. The identification of the Staphylococcus genus was done by microscopic observation, Gram-staining and catalase determination. All staphylococcal strains were checked for purity and tested for their ability to coagulate citrated rabbit plasma. Further identification, biochemical system "API Staph system" (both from Bio Merieux, Marcy-l'Etoile, France) and the Microscan ${ }^{\circledR}$ (automate WalkAway® 40/96 DADE BEHRING: designed for use for identification to the species level and/or antimicrobial agent susceptibility of facultative and some fastidious aerobic gram positive cocci) were used to determine the species more precisely.

\section{Biotyping}

Each of the $40 \mathrm{~S}$. aureus strains isolated from fresh milk, cheese [jben] and whey [lben] was biotyped following the simplified system proposed by Devriese [15]. Characteristics examined were staphylokinase production, $\beta$-hemolysin, coagulation of bovine plasma and the type of 
growth on crystal violet. The strains were classified in various biotypes: human $(A)$, bovine $(C)$, ovine (D) and poultry (B). The strains that could not be classified in one of the biotypes was regarded as being non host specific [Unspecified] .

\section{Coagulase Gene Typing}

DNA of all the bacteria was extracted using the InstaGenee Matrix (Bio-Rad, Marnes-la-Coquette, France). The kit was used according to the manufacturer's instructions. From each sample, 5 $\mu \mathrm{l}$ of total cellular DNA were then evaluated by PCR with appropriate primers and cycling conditions. The PCR primers used for the identification of the coa genes were those reported by Hookey et al. [16]. Sequences of the primers were as follows:

Coa1: 5'-ATA GAG ATG CTG GTA CAG G-3', Coa2: 5'-GCT TCC GAT TGT TCG ATG C-3'.

For PCR reaction, the conditions described by Hookey et al. [16] were used. Amplification was conducted in a thermal cycler (iCycler; Bio-Rad Laboratories) as follows: An initial denaturation at $94^{\circ} \mathrm{C}$ for 45 seconds. The cycling proceeded for 30 cycles of $94^{\circ} \mathrm{C}$ for 20 seconds, $57^{\circ} \mathrm{C}$ for 15 seconds, and $70^{\circ} \mathrm{C}$ for 15 seconds with a final step at $72^{\circ} \mathrm{C}$ for 2 minutes. The tubes were cooled until they were used.

The PCR products was separated in $2 \%$ (wt/vol) agarose gel in the presence of ethidium bromide then photographed and analysed under UV light in the gel-doc system (BioRad, MuK nchen, Germany). The 100-bp DNA ladder (EZ Load 100 bp, Bio-Rad Laboratories) was used as a molecular marker.

\section{Antibiotic susceptibility test}

The antimicrobial susceptibility tests were performed by dilution in liquid medium and application to substrates dehydrated in a MuellerHinton medium containing calcium and magnesium or other factors critical for the bacterial growth. After inoculation with a bacterial suspension and incubation at $35^{\circ} \mathrm{C}$ for 16 hours, Minimal Inhibitory Concentration (MIC) was determined by the lowest antibiotic concentration presenting growth inhibition. For these panels, dilutions of antibiotics used correspond to the concentrations equivalent to the critical concentrations of the Committee of Antibiorgamme of French Company of Microbiology (CA-FCM). All the identified Staphylococcus strains were tested for pristinamicyn (Prs), teicoplanin (Tei), vancomycin (Van), oxacillin (Ox), penicillin $(P)$, Augmentin (Aug), tetracyclline (Te), fosfomycine (Fos), gentamicin (Gm), erythromycin (E), lincomycin (Lin), kanamycin (K), tobramycin (To), chloramphénicol (C), rifampycin (Rif), nitrofurontoin (Fd), fusidic acid (FA), trimethoprim/sulfamethoxazole (T/S), and pefloxacin (Pef).

\section{Results}

Identification of Staphylococcus Species

The 100 staphylococci isolated from the 81 samples of milk and dairy products examined (27 lben, 27 milk and 27 jben) were isolated and observed on Baird Parker, then tested for the production of coagulase on rabbit plasma and finally identified by their biochemical characteristics. They could be divided into 4 groups: the first comprised the species $S$. aureus with a total of 40 isolates (40\%); the second and third were represented respectively by the species $S$. intermedius, with 2 isolates $(2 \%)$ and $S$. hycius hycius with 4 isolates (4\%); the last contained 54 $(54 \%)$ isolates that were found to be coagulase negative staphylococci (CNS) (Table 1).

Table 1. Distribution of staphylococci isolated from milk, Iben and jben.

\begin{tabular}{|c|c|c|c|c|}
\hline $\begin{array}{l}\mathscr{\infty} \\
\frac{0}{0} \\
0 \\
0\end{array}$ & $\stackrel{\underline{y}}{\underline{\underline{\Sigma}}}$ & 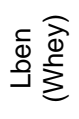 & 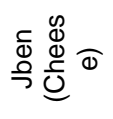 & $\stackrel{\bar{\pi}}{\circ} \stackrel{0}{\circ}$ \\
\hline S. arlettae & 2 & 0 & 0 & $2(2 \%)$ \\
\hline S. aureus & 10 & 16 & 14 & $40(40 \%)$ \\
\hline S. auricularis & 0 & 0 & 3 & $3(3 \%)$ \\
\hline S. cohnii & 1 & 4 & 1 & $6(6 \%)$ \\
\hline S. epidermidis & 3 & 3 & 1 & $7(7 \%)$ \\
\hline S. gallinarum & 1 & 0 & 0 & $1(1 \%)$ \\
\hline S. hyicus hyicus & 1 & 2 & 1 & $4(4 \%)$ \\
\hline S. intermedius & 0 & 1 & 1 & $2(2 \%)$ \\
\hline S. hominis & 2 & 2 & 3 & $7(7 \%)$ \\
\hline S. lentus & 2 & 2 & 1 & $5(5 \%)$ \\
\hline S. sciuri & 0 & 1 & 0 & $1(1 \%)$ \\
\hline S. simulans & 1 & 2 & 3 & $6(6 \%)$ \\
\hline S. xylosus & 4 & 2 & 2 & $8(8 \%)$ \\
\hline
\end{tabular}


Biotypes of Staphylococcus aureus

The data shows that of the four coagulase types, $18(45 \%)$ have been reported to be of bovine origin (C) and more dominant than the other biotypes. The distribution of the remaining biotypes for the isolates of the $\mathrm{S}$. aureus were respectively 12 (30\%), $6(15 \%)$, and $4(10 \%)$ for the biotypes $\mathrm{B}$ (poultry), A (human) and unspecified (IND). Isolates that could not be determined as biotypes $A, B, C$ bovine or $C$ ovine according to Devriese's scheme were classified as an unspecified biotype. It can be noted that this biotype was often very similar to the $C$ bovine biotype.

\section{Gene Amplification Products}

According to culture, chemical properties, and the positive tube coagulase test, 40, 4 and 2 isolates used in the present study could be respectively identified as $S$. aureus, $S$. intermedius and $S$. hyicus. The coagulase gene typing was effective in subdividing strains of $S$. aureus from milk products [L, $\mathrm{J}$ and $\mathrm{M}$ ] as all yielding a PCR amplification product. In contrast, no amplification product could be obtained from the strains of the other coagulase positive staphylococcal species investigated.

The 40 isolates of $S$. aureus could be differentiated from each other on the basis of two characteristics of their PCR products, i.e., the presence of one or two PCR products and their size(s). A single PCR product with sizes of approximately $400 \mathrm{pb}, 560 \mathrm{pb}$ and $720 \mathrm{pb}$ from 37 isolates was found, while two products from 3 isolates were amplified. The sizes of the PCR products ranged approximately from 400 to approximately $900 \mathrm{bp}$ (Figure 1A and 1B). Two isolates of coagulase-negative and positive staphylococci ( $S$. epidermidis which served as negative controls and $S$. intermedius) produced no coagulase gene products following PCR amplification (Figure 1A).

\section{Antimicrobial Susceptibility}

Antibiotic-resistance patterns of the CNS and CPS strains isolated from milk and milk product sources in North Morocco are shown in Table 2. The antimicrobial susceptibility profile revealed a high resistance of $S$. aureus to penicillin (50\%). A low prevalence of resistance was detected for tetracyclline $(25 \%)$, oxacillin $(15 \%)$. Few strains were resistant to erythromycin (10\%); lincomycin $(10 \%)$ and kanamycin (10\%). Coagulase-negative staphylococci are more susceptible to penicillin. The overall penicillin resistance rate for CNS was $37.8 \%$.

Figure 1. Electrophoretic profile, in $2 \%$ agarose gel, of polymerase chain reaction (PCR) products of $S$. aureus coagulase gene isolated from milk and milk products (whey and jben):

(A) Isolates with only 1 amplicon. Lane 1: molecular weight marker $100 \mathrm{bp}$ amplicon; Lane 2: 400 bp amplicon. Lanes 3, 4: 560 bp amplicon. Lanes 5, 6: 720 bp amplicon; lane 7: negative controls, $S$. epidermidis; lanes 8 : $S$. intermedius.

(B) Isolates with 1 amplicon or with 2 amplicons. Lane 1: molecular weight marker 100 bp amplicon; Lane 2: 700 bp amplicon. Lane 3: 560-800 bp amplicon; Lane 4: 480-700 bp amplicon; Lane 5: $900 \mathrm{bp}$; Lane 6: $700 \mathrm{bp}$ amplicon; Lane 7: 700 bp amplicon; Lane 8 : 480-700 bp amplicon.

(A)

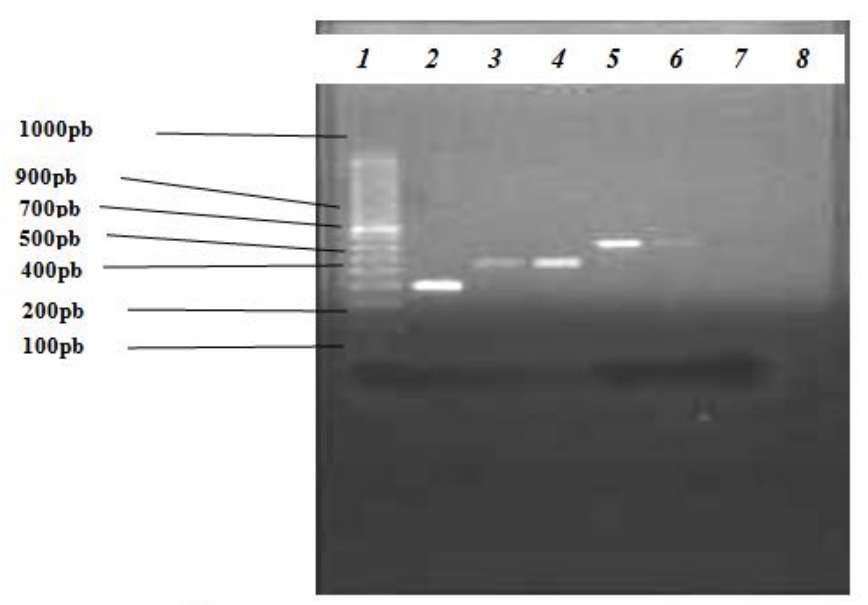

(B)

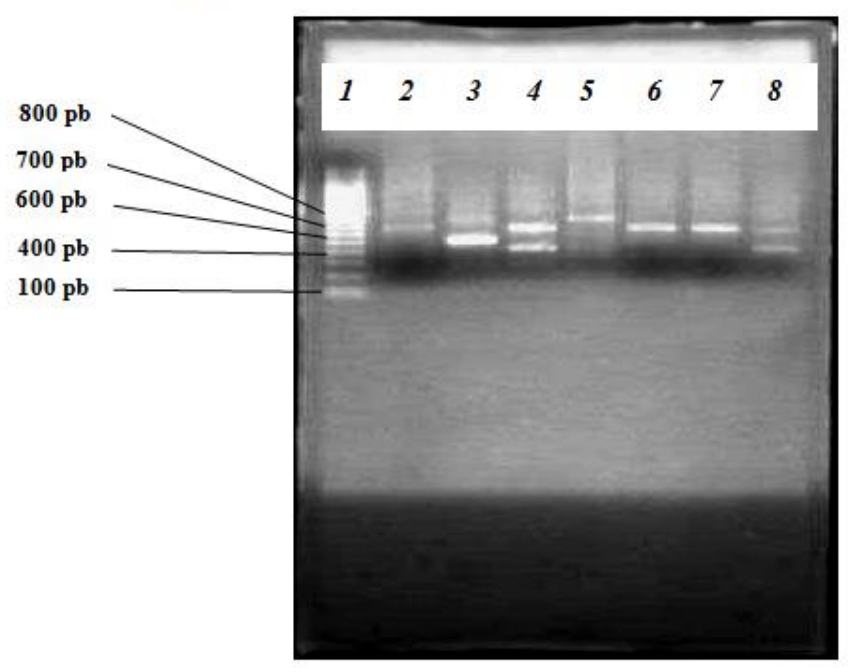

According to our results, it was also shown that $35 \%, 10 \%$ and $29.7 \%$ of CNS obtained was 
resistant to kanamycin, gentamicin and erythromycin, respectively.

Table 2. Frequencies of antimicrobial resistance in Staphylococcus aureus and SCN.

\begin{tabular}{|c|c|c|c|}
\hline Antibiotic & ஸे & $\begin{array}{l}z \\
\text { ¿ } \\
\text { ঃ }\end{array}$ & $\begin{array}{c}\text { The most resistant } \\
\text { species } \\
\text { of SCN }\end{array}$ \\
\hline (Prs) Pristinamicyn & 0 & 10.8 & S.lentus \\
\hline (Tei) Teicoplanin & 0 & 10.8 & S.lentus \\
\hline (Van) Vancomycin & 0 & 10.8 & S.lentus \\
\hline (Ox) Oxacillin & 15 & 29.7 & S.lentus \\
\hline (P) Penicillin & 50 & 37.8 & S. lentus + NID \\
\hline (Aug) Augmentin & 0 & 0 & \\
\hline (Te) Tetracyclline & 25 & 16.2 & S. auricularis \\
\hline (Fos) Fosfomycine & 0 & 10.8 & S. xylosus \\
\hline (Gm) Gentamicin & 5 & 10.8 & NID \\
\hline (E) Erythromycin & 10 & 29.7 & S. lentus \\
\hline (Lin) Lincomycin & 10 & 29.7 & S. lentus \\
\hline (K) Kanamycin & 10 & 35 & NID \\
\hline (To) Tobramycin & 5 & 18.9 & NID \\
\hline (C) Chloramphenicol & 5 & 2.7 & S. cohnii \\
\hline (Rif) Rifampycin & 0 & 5.4 & $\begin{array}{l}\text { S. lentus + S. } \\
\text { auricularis }\end{array}$ \\
\hline (Fd) Nitrofurontoîn & 0 & 0 & \\
\hline \multirow{2}{*}{$\begin{array}{l}\text { (FA) fusidic Acid } \\
\text { (T/S) trimethoprim/ } \\
\text { Sulfamethoxazole }\end{array}$} & 0 & 10.8 & S. lentus \\
\hline & 0 & 0 & \\
\hline (Pef) Pefloxacin & 0 & 21.6 & NID \\
\hline
\end{tabular}

No resistance for glycopeptides was observed for S. aureus; however, $10.8 \%$ of CNS showed decreased susceptibility to teicoplanin and vancomycin.

For the remainder antibiotics, we found an increased resistance to lincomycin 29.7\%, pefloxacine $21.6 \%$ and tobramycin $18.9 \%$. Finally it should be noted that none of the milk and milk product isolates had augmentin (amoxicillinclavulanate) resistant strains.

\section{Discussion}

The results showed that coagulase-negative staphylococcal (CNS) species more frequently occurred in milk and milk products (54\%). This high number of CNS isolated may be due to the bad conditions of hygiene during milking and lack of hygienic measures in the manufacturing, preparation, handling and storage of whey and jben. Also, the method of their sale is entirely based on tradition. Because CNS are a part of the normal teat skin flora and mucosa of humans and animals, some species are also found free-living in the environment [17], and therefore are a common cause of contamination of milk and milk product. In addition, unpasteurized milk may contain CNS if the cow suffers from mastitis, an inflammation of the udder caused by CNS.

In the past, CNS were often regarded as skin flora opportunists but emerging data now indicates that they are associated with several sub-clinical and clinical infections [18-22].

It appears from the biotyping results with regard to the $40 \mathrm{~S}$. aureus strains that a high proportion of the strains belonged to the $\mathrm{C}$ bovine ecovar. Approximately $45 \%$ of the $S$. aureus isolates belong to this biotype indicating the preponderance of the contaminations coming from raw milk used. Most literature indicates that $S$. aureus appears in milk from cows afflicted with mastitis [23]. The data from literature also suggest that the persistent colonization of the teat skin occurs and may be an important predisposing factor for $S$. aureus contaminations. [24]. About $30 \%$ of our strains possessed the characters of the $B$ biotype, a fact easily explained by the interchange of staphylococci among different animals due to their frequent contact [25]. Identification of $A$ biotype strains in the other group of isolates suggests contamination of the products with staphylococci of human origin during manufacture or distribution. [26]

Routine bacteriological tests used in the identification of $S$. aureus, such as mannitol fermentation, DNAse production, VP, etc., are not enough for definitive characterization [27]. Nevertheless, coagulase production is one of the most reliable criteria for the identification of $S$. aureus [28]. The PCR products of the gene encoding staphylococcal coagulase displayed gene polymorphisms and allowed a genotypic characterization of the bacteria. Length and sequence of the polymorphisms of the coagulase gene and its use for genotypic characterization of $S$. aureus had been already shown [16,29-33]. The coagulase gene has been found polymorphic and 
genotypically variable among $S$. aureus strains isolated in this study. The polymorphism obtained was clearly revealed due to multi-allelic forms at the 3- end of the gene (tandem repeats) which differ in their sequences and restriction sites. Phenotypic variations were demonstrated clearly in the production of staphylocoagulases among milk, whey and jben isolates which may be due to polymorphism of the gene. In order to assess the feasibility of using coagulase gene typing as an epidemiological marker, a large number of isolates from different geographic regions and different milk products were analyzed. The ease of analysing coagulase gene polymorphism within a large number of strains and the multiple distinct polymorphic patterns generated support the use of this technique in epidemiological investigations of S. aureus mastitis [30].

The primer pair amplified more than one PCR product in 3 isolates, which suggests the presence of different allelic forms of the $\operatorname{coA}$ gene. With the PCR method, an amplification product was not observed for the DNA of other coagulase-positive species of Staphylococcus (S. hyicus hyicus and $S$. intermedius). These results are in accordance with Aarestrup et al. [34], who studied the amplification of sequences of the $c 0 A$ gene in 187 strains of $S$. aureus, 10 strains of $S$. intermedius, 3 strains of $S$. hyicus, 1 strain of $S$. delphini and 1 strain of $S$. schleiferi subspecies coagulans and verified the presence of bands only in $S$. aureus [35]. These authors suggested that coagulase gene typing might also be useful as an additional identification criterion to differentiate among coagulase positive staphylococci [36, 34]. The extensive polymorphism observed suggests that the coagulase gene may be an important virulence determinant for this organism's characterization [30].

In our study, the highest resistance was registered for penicillin $\mathrm{G}$ by both $S$. aureus (50\%) and CNS $(37,5 \%)$ strains obtained from milk, whey and jben. This is not surprising because ampicillin is one of the most commonly used antibiotics for treatment of infections in humans and animals [37]. Different rates of penicillin resistance have been reported for $S$. aureus and CNS obtained from different sources. Acco et al. showed that $70 \%$ of strains of $S$. aureus isolated from food handlers were resistant to penicillin [38]. Benhassen et al. reported that $64 \%$ and $22.6 \%$ of the $S$. aureus and CNS strains respectively isolated from goat mastitis were resistant to penicillin G [22]. Messadi et al. presented very similar data with $64 \%$ against $18.6 \%$ [39]. No resistance against augmentin (amoxicillinclavulanate) was observed both from strains of $S$. aureus and CNS in this study. Thus, the results indicate that the majority of antimicrobial resistance in $S$. aureus and CNS isolates could be due to production of $\beta$-lactamases. El-Ghodban et al. found that $75 \%$ of Libyan $S$. aureus strains originating from food were resistant to penicillin and were positive for $\beta$-lactamase [40]. Ann Hébert et al. showed that all seven isolates of CNS strains from hospital were $\beta$-lactamase positive and resistant to penicillin but were susceptible to the other antibiotics tested [41]. The second-highest resistance was observed to tetracycline (25\%) and oxacillin (15\%) for $S$. aureus strains, and to tetracycline, oxacillin, erythromycin, lincomycin, kanamycin, tobramycin and pefloxacin for CNS, especially $S$. lentus. Little to no resistance was seen with the other antimicrobial agents tested $(0$ to $10 \%$ ). The findings suggest the requirement of proper use of $\beta$-lactam antibiotics for mastitis therapy. To prevent the unnecessary use of $\beta$ lactams and to achieve effective therapy, isolation of the microorganisms and determination of antimicrobial susceptibility is essential before the start of any treatment [42].

In conclusion, our results showed high levels of CNS contamination in the samples of raw milk, Iben and jben. In the classification scheme of Devriese (1984), about $45 \%$ of all the CPS strains tested were found to belong to $C$ (bovine) biotype. A high genotypic uniformity of different-sized coagulase gene amplicons was also demonstrated. The PCR method based on coagulase gene typing is able on one hand to identify and discriminate between coagulasepositive Staphylococcus species and on the other hand to classify all $S$. aureus strains.

We conclude also that sanitary measures are needed to improve the hygienic conditions during milking and manufacturing of jben and lben, in order to guarantee the quality of these highly popular products in North Morocco.

Finally, it should be noted that for all the $S$. aureus strains isolated from all samples, none were resistant to teicoplanin, augmentin (amoxicillin-clavulanate) or vancomycin. This is 
important, since although MRSA strains may pose a therapeutic problem for staphylococcal infection, they may be controlled by the use of these antibiotics.

\section{Acknowledgements}

The authors thank the institute Pasteur of Morocco for financial support. This work was conducted at the Department of Research and Laboratory of Food Microbiology at the Institute Pasteur of Morocco, Tanger.

\section{References}

1. Jablonski LM and Bohach GA (1999) Staphylococcus aureus, p. 353-375. In M. P. Doyle, L. R. Beuchat, and T. J. Montville (ed.) Food microbiology: fundamentals and frontiers. ASM Press, Washington DC.

2. Jorgensen HJ, Mork T, Caugant DA, Kearns A, Rørvik LM (2005) Genetic Variation among Staphylococcus aureus strains from Norwegian Bulk Milk. Applied and environmental microbiology. p. 8352-8361.

3. Le Loir Y, Baron F, Guatier M (2003) Staphylococcus aureus and food poisoning. Genet Mol Res 2: 63-76.

4. Stewart CM, Cole MB, Schaffner DW (2003) Managing the Risk of Staphylococcal Food Poisoning from CreamFilled Baked Goods to Meet a Food Safety Objective. Journal of Food Protection (66) 7: 1310-1325.

5. Payne D. and. Wood JM (1974) The incidence of enterotoxin production in strains of Staphylococcus aureus isolated from food. J Applied Bacteriol 319-25.

6. Bone FJ, Bogie D, Morgan-Jones SC (1989) Staphylococcal food poisoning from sheep milk cheese. Epidemiology and Infection 103: 449-458.

7. Bryan FL (1983) Epidemiology of milk-borne diseases. Journal of Food Protection 46: 637-649.

8. Evenson ML, Hinds MW, Bernstein RS, Bergdoll MS (1988) Estimation of human dose of staphylococcal enterotoxin A from large outbreak of staphylococcal food poisoning involving chocolate milk. International Journal of Food Microbiology 7: 311-316.

9. Gross E M, Weizman Z, Picard E, Mates A, Sheiman R, Platzner N, and Wol A (1988) Milk borne gastroenteritis due to Staphylococcus aureus enterotoxin B from a goat with mastitis. American Journal of Tropical Medicine and Hygiene 39: 103-104.

10. Holmberg SD and Blake PA (1984) Staphylococcal food poisoning in the United States. New facts and old misconceptions. Journal of American Medical Association 1: 487-489.

11. Wieneke AA, Roberts D, Gilbert RJ (1993) Staphylococcal food poisoning in United Kingdom, 196990. Epidemiology and Infection 110: 519-531.

12. Oliver SP, Jayarao BM, Almeida RA (2005) Foodborne Pathogens, Mastitis, Milk Quality, and Dairy Food Safety. NMC Annual Meeting Proceedings.

13. Soomro $A H$, Arain MA, Khashkeli M, Bhutto B, Memon AQ (2003) Isolation of Staphylococcus aureus from Milk Products Sold at Sweet-meat Shops of Hyderabad. On Line Journal of Biological Sciences 3 (1): 91-94.
14. Hamama A. (1989) Qualité bactériologique des fromages frais marocains. Options Méditerraneennes-Série Séminaires - $n^{\circ}$ 6: 223-227.

15. Devriese LA (1984) A simplified system for biotyping Staphylococcus aureus strains isolated from different animal species. J Appl Bacterial 56: 215-220.

16. Hookey JV, Richardson JF, Cookson BD (1998) Molecular typing of Staphylococcus aureus based on PCR restriction fragment length polymorphism and DNA sequence analysis of the coagulase gene. J Clin Microbiol 36:1083-1089.

17. Normanno G, Firinu A, Virgilio S, Mula G, Dambrosio A, Poggiu A, Decastelli L, Mioni R, Scuota S, Bolzoni G, Di Giannatale E, Salinetti AP, La Salandra G, Bartoli M, Zuccon F, Pirino T, Sias S, Parisi A, Quaglia NC, Celano, GV (2005) Coagulase-positive Staphylococci and Staphylococcus aureus in food products marketed in Italy. International Journal of Food Microbiology 98: 7379.

18. Ontario Ministry of Agriculture (1999), Interpreting Milk Culture Reports: Coagulase-negative Staphylococcus Food and Rural Affairs "Animal Health News" Vol 7, No. 4.

19. Bes M, Guerin-Faublee V, Meugnier H, Etienne J, Freney $J$ (2000) Improvement of the identification of staphylococci isolated from bovine mammary infections using molecular methods. Vet Microbiol 71:287-294.

20. Pyörälä S (1995) Staphylococcal and streptococcal mastitis. In: Sandholm M, Honkanem-Busalski T, Kaartinem I, Pyörälä M (eds) The bovine udder and mastitis. Edition Helsinki, 143-148.

21. Fabre JM, Morvan $H$, Lebreux $B$, Houffschmitt $P$, Berthelot $X$ (1997) Estimation de la fréquence des différents germes responsables de mammites en France. Bull Group Techn Vet 5-B-573, 9-15.

22. Benhassen S, Messadi L, Benhassen A (2003) Identification et caractérisation des espèces de Staphylococcus isolées de lait de vaches atteintes ou non de mammite. Ann Méd Vét 147: 41-47.

23. Al-Tahiri R (2005) A Comparison on Microbial Conditions between Traditional Dairy Products Sold in Karak and Same Products Produced by Modern Dairies. Pakistan Journal of Nutrition 4 (5): 345-348.

24. Roberson JR, Fox LK, Hancock DD, Gay JM, Besser TE (1998) Sources of Intramammary Infections from Staphylococcus aureus in Dairy Heifers at First Parturition. J Dairy Sci 81: 687- 693.

25. Dimitracopoulos G, Sakellariou C, Papavassiliou J (1976) Staphylococci from the Feces of Different Animal Species: Biotypes of Staphylococcus aureus Strains of Sheep and Goat Origin. Applied and Environmental Microbiology 32: 53-55.

26. Hajek V (1978) Identification of Enterotoxigenic Staphylococci from Sheep and Sheep Cheese. Applied and Environmental Microbiology 35: 264-268.

27. Vieira-da-Motta O, Folly MM, Sakyiama CCH (2001) Detection of different Staphylococcus aureus strains in bovine milk from subclinical mastitis using PCR and routine techniques. Brazilian Journal of Microbiology 32:27-31.

28. Turutoglu H, Tasci F, Senay E (2005) Detection of Staphylococcus Aureus in Milk by Tube coagulase Test. Bull Vet Inst Pulawy 49: 419-422. 
29. Annemüller C, Lämmler C, Zschöck M (1999) Genotyping of Staphylococcus aureus isolated from bovine mastitis. Vet Microbiol 69:217-224.

30. Goh SH, Byrne SK, Zhang JL, Chow AW (1992) Molecular typing of Staphyl- ococcus aureus on the basis of coagulase gene polymorphism. J Clin Microbiol 30: $1642-1645$.

31. Shopsin B, Gomez M, Waddington M, Riehman M, Kreiswirth BN (2000) Use of coagulase gene (coa) repeat region nucleotide sequences for typing of methicillinresistant Staphylococcus aureus strains. J Clin Microbiol 38: 3453-3456.

32. Stephan R, Annemüller $\mathrm{C}$, Hassan $\mathrm{AA}$, Lämmler $\mathrm{C}$. (2000) Characterization of enterotoxigenic Staphylococcus aureus strains isolated from bovine mastitis in north-east Switzerland. Vet Microbiol 2051: 110.

33. Su C, Kanevsky I, Jayarao BM, Sordillo LM (2000) Phylogenetic relationships of Staphylococcus aureus from bovine mastitis based on coagulase gene polymorphism. Vet Microbiol 71: 53-58.

34. Aarestrup FM, Dangler CA, Sordillo LM (1995) Prevalence of Coagulase Gene Polymorphism in Staphylococcus aureus Isolates Causing Bovine Mastitis. Can J Vet Res 59: 124-128.

35. Da Silva WP, Silva JA, De Macedo MRP, De Araújo MR, Mata MM, Gandra EA (2003) Identification of Staphylococcus aureus, S. intermedius and $S$. hyicus by PCR amplification of $\operatorname{co} A$ and Nuc genes. Brazilian Journal of Microbiology 34 (Suppl.1):125-127.

36. Da Silva ER and Da Silva N (2005) Coagulase gene typing of Staphylococcus aureus isolated from cows with mastitis in south-eastern Brazil. The Can J Vet Res 69: 260-264.
37. Gundogan N, Citak S, Yucel N, Devren A (2005) A note on the incidence and antibiotic resistance of Staphylococcus aureus isolated from meat and chicken samples. Meat Science 69: 807-810.

38. Acco M, Ferreira FS, Henriques JAP, Tondo EC (2003) Identification of multiple stains of Staphylococcus aureus colonizing nasal mucosa of food handlers. Food Microbiology 20: 489-493.

39. Messadi L, Benmiled L, Haddad N (1991) Mammites bovines en Tunisie: bactéries responsables et antibiorésistance. Rev Méd Vét 142: 313-319.

40. El-Ghodban A, Ghenghesh KS, Màrialigeti $\mathrm{K}$, Esahli $\mathrm{H}$, Tawil A (2006) PCR detection of toxic shock syndrome toxin of Staphylococcus aureus from Tripoli, Libya. Journal of Medical Microbiology 55: 179-182.

41. Ann Hébert G, Cooksey RC, Nancye C, Clark NC Hill BC, Jarvis WR, Thornsberry C (1988) Biotyping CoagulaseNegative Staphylococci. Journal of clinical microbiology 1950-1956.

42. Güler L, Ok Ü, Gündüz K, Gülcü Y, Hadimli HH (2005) Antimicrobial Susceptibility and Coagulase Gene Typing of Staphylococcus aureus Isolated from Bovine Clinical Mastitis Cases in Turkey. J Dairy Sci 88: 3149-3154.

Corresponding Author: Mohammed Abid, Département de Recherche, Laboratoire de Biologie moléculaire, Institut Pasteur du Maroc-Tanger-N¹ Rue Cortobi Plateau Marshan-Tanger.

Phone: 039931111

Fax: 039932299

E-mail: mohammed.abid@pasteur.ma

Conflict of interest: No conflict of interest is declared. 